\title{
Advantages and Perspectives of Teaching in Outpatient Clinics: A Systematic Review
}

\author{
Hani Almoallim 1,2,3, Joan Minguet1, Khaled Albazli1,4, Manal Alotaibi1,2, Samar Alwafi, ${ }^{1,5}$, \\ Maun Feteih ${ }^{6}$ \\ ${ }^{1}$ Alzaidi Chair of Research in Rheumatic Diseases, Umm Alqura University, Makkah, Saudi Arabia \\ ${ }^{2}$ Department of Medicine, Medical College, Umm Alqura University, Makkah, Saudi Arabia \\ ${ }^{3}$ Department of Medicine, Dr. Soliman Fakeeh Hospital, Jeddah, Saudi Arabia \\ ${ }^{4}$ Department of Medicine, Medical College in Alqunfudah, Umm Alqura University, Makkah, Saudi Arabia \\ ${ }^{5}$ Department of Dermatology, King Abdulaziz Medical City, Jeddah, Saudi Arabia \\ ${ }^{6}$ Department of Medicine, King Faisal Specialist Hospital and Research Centre, Jeddah, Saudi Arabia \\ Email: hanialmoallim@gmail.com, bazlikhaled@gmail.com
}

Received 21 August 2015; accepted 18 September 2015; published 21 September 2015

Copyright (C) 2015 by authors and Scientific Research Publishing Inc.

This work is licensed under the Creative Commons Attribution International License (CC BY).

http://creativecommons.org/licenses/by/4.0/

(c) (i) Open Access

\begin{abstract}
Although the number of patients seen in outpatient clinics far surpasses those managed in inpatient settings, many medical training programs lack outpatient clinic teaching initiatives. Thus, we have conducted a systematic review of the literature in order to raise awareness of the important role that outpatient clinics can play in enhancing medical education, and to assess current perspectives on improving outpatient training. Our analysis reveals that outpatient clinics can offer an efficient and holistic view of patient care, while covering a wide range of general and specialty medical practices. Moreover, several fundamental skills can be acquired by students in outpatient clinics, which effectively combine elements encountered in routine wardbased teaching (etiology, history, physical examination, laboratory tests, and therapy) with those found in ambulatory care (continuity, context, health education, economics, and responsibility). Approaches to teaching in an outpatient setting vary greatly, with extensive differences in levels of supervision and feedback evident. It is clear that, at present, there is no general consensus on the best strategy for realizing the potential of outpatient clinics in the training of students and junior doctors. With the changing face of health systems, the identification of methods by which maximal benefits of this setting can be achieved would be highly advantageous for future medical trainees.
\end{abstract}

\section{Keywords}

Outpatient Clinic, Ambulatory Care, Teaching, Training, Medical Education 


\section{Introduction}

To effectively deliver patient care, physicians must attain a high level of knowledge and advanced skills during their training. In this regard, shifting from informational learning strategies to hands-on approaches in medical education has enhanced training programs (Bentley et al., 1989). Thus, current medical instruction is based on the premise that students and residents learn best by participating, under supervision, in the day-to-day care of patients (Bentley et al., 1989).

Although case-based teaching approaches may be desirable, changes in patient management within hospital wards currently provides fewer opportunities for training in core clinical areas (Fincher \& Albritton, 1993; Krackov et al., 1993). Indeed, modern methods and patient expectations have contributed to shorter hospital stays, with patients that present common conditions (even acute cases) now routinely managed as outpatients. Lawson and Moss reported that the average inpatient stay for acute specialties in the UK dropped from 11.3 to 6.1 days from 1970 to 1990 (Lawson, 1993). Therefore, as much as 70\% of hospital-patient contact now occurs within outpatient settings (Dent, 2005). As a result, inpatients are often critically ill and only represent subspecialties, making them less characteristic of standard medical practice (Fincher \& Albritton, 1993, Seabrook et al., 1997).

For this reason, modern medical education has increasingly shifted toward providing real world exposure by employing ambulatory services as educational tools (Harden et al., 1999, Wieland et al., 2013). Ambulatory care refers to all parts of the hospital that provide outpatient consultation or diagnostic/therapeutic procedures that do not require patient admission (McGee \& Irby, 1997). However, even though the number of patients seen in outpatient clinics (OPCs) far surpasses those managed in inpatient settings, it is questionable whether they are being sufficiently utilized for teaching purposes (Dent, 2005; Meyers et al., 2007).

Here, we discuss the potential benefits of teaching in an outpatient setting, and how the different approaches are viewed by the trainees. Based on a critical review of the literature, we evaluate the advantages and current perspectives associated with such methodology.

\section{Methods}

\subsection{Systematic Search of the Literature}

Electronic literature searches were performed using PubMed in July 2014. To identify information on current perspectives and advantages associated with teaching in outpatient settings, the following terms were searched in various combinations "outpatient clinic", "ambulatory", "training”, "residents", "education”, "outpatient teaching", "feedback" and "supervision". The search was then extended by manual screening of the references to identify additional supporting material.

\subsection{Selection Criteria}

The selected articles reported results or perspectives that directly yielded insight into outpatient education and were written in English. As per Best Evidence Medical Education (BEME) review guidelines, studies were not excluded based on the type of study design. Relevant articles were evaluated and discussed by two reviewers in order to assess quality. A flow diagram outlining our systematic literature search is shown in Figure 1.

\section{Findings}

\subsection{Key Advantages of OPC Training}

It has been proposed that clinical teaching opportunities should involve treating and managing patients in OPCs, operating rooms, and hospitals in order to develop a system of evidence-based medical education that promotes continuous development of competencies and produces self-directed learners (Kotur et al., 2012). However, although the number of patients seen in outpatient settings has grown, development of OPC training initiatives has been limited (Dent, 2005; Meyers et al., 2007). Ultimately, the outpatient setting has the potential to provide numerous benefits, including greater exposure to cases, experience with diverse clinical topics, and efficient development of doctor-patient relationships.

\subsubsection{Volume and Diversity of Case Exposure}

There is some evidence that a higher volume of cases improves the knowledge and skills acquisition of medical 


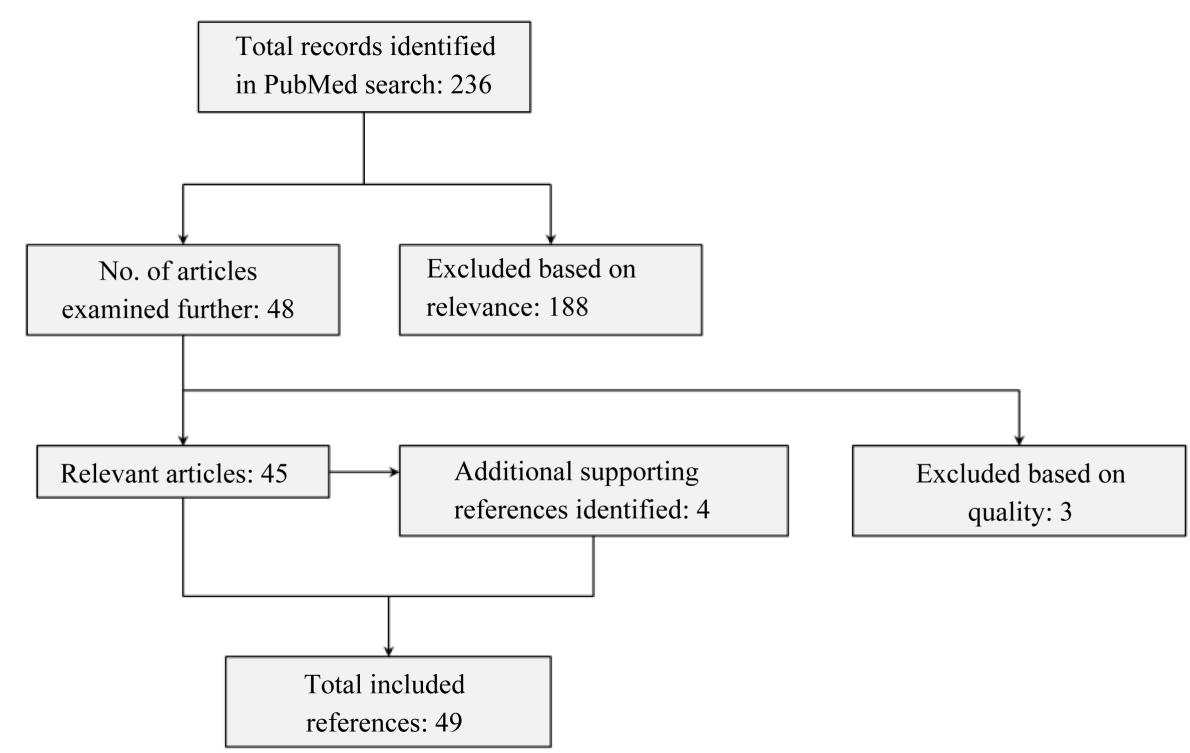

Figure 1. Flow diagram showing our systematic literature search on outpatient education.

trainees. Albert et al. found that the volume of cases logged by individual medical students in a neurology OPC correlated with their performance on knowledge and clinical skill tests (Albert et al., 2014). In a urology setting, Kerfoot et al. reported an increase in the number of patient encounters in an outpatient setting, which was associated with perceived skills improvement by the medical students involved in the study (Kerfoot \& DeWolf, 2002). On the other hand, it has been shown that participation in more outpatient surgeries or surgical clinics yielded no improvement in written examination performance (Chatenay et al., 1996, Neumayer et al., 1998, Seabrook et al., 1998). As there is a wide range of general and specialty medical practices represented within OPCs, it has been acknowledged that ambulatory care settings are advantageous for maximizing learning opportunities (Stewart et al., 2005). To ensure a more complete education, medical trainees need to be exposed to a wide variety of cases (Stahl et al., 2014). Kerfoot et al. compared inpatient and outpatient urology training, and found that students randomized to OPC-based urology education were likely to gain exposure to a greater diversity of patients with common urological problems (Kerfoot \& DeWolf, 2002). This resulted in the students reporting improvements in a range of skills, in particular, those regarding physical examinations. Moreover, they perceived that they had learnt more about given curricular topics and skills (Kerfoot \& DeWolf, 2002). In a pediatric setting, medical students who completed a short rotation in an outpatient department reported that they had gained knowledge regarding a range of common conditions, in addition to improved confidence in handling patients and their families (Behmanesh et al., 2014). Post-rotation test scores were also found to be higher than those of students that had been based in an inpatient environment. Similarly, in a study regarding clinically challenging cases, residents perceived that exposure to more complex patients in OPCs made valuable contributions to their learning (Cook et al., 2008). However, it was also found that subsequent knowledge test scores were unaffected.

\subsubsection{Increased Patient Diversity}

Several skills can be acquired by students in OPC settings (e.g., continuity, context, health education, and responsibility), along with fundamental elements that are normally encountered in routine ward-based teaching (e.g., etiology, history, physical examination, laboratory tests, and therapy). Furthermore, OPCs can present specialized learning opportunities to medical trainees. The outpatient environment often allows valuable exposure to social, psychological, financial, and ethical aspects of patient management, which may not be experienced in inpatient settings (Cook et al., 2008; Moon et al., 2009; Carrese et al., 2011; Sturm et al., 2011). Notably, knowledge of these topics is essential for effectively treating patients in the modern healthcare system. Yikilkan and colleagues even suggested that training should take place at various primary care units according to the sociodemographic characteristics of the country (Yikilkan et al., 2013). In this regard, experiencing differences between rural and urban outpatient settings can diversify training. Therefore, some medical schools have begun to implement requirements for rural internships, when appropriate, to meet the unique needs of their re- 
gion (Sen Gupta et al., 2008). In addition, there is a major trend to develop community-based education programs, which can provide contextual learning and allow trainees to acquire the competencies needed to deliver healthcare in local communities. However, in order to efficiently implement community-based programs, structured models and tools for evaluating the outcomes of these approaches need to be established (Mariam et al., 2014). Interestingly, free clinics also represent platforms for community-based continuity education that can offer unique social and economic perspectives (Pincavage et al., 2013).

\subsubsection{Cultivating Effective Doctor-Patient Interactions}

Outpatient departments often avoid some of the pressures associated with availability and care commitments that are inevitable within inpatient settings. Thus, they might represent ideal environments for trainees to develop essential patient interview and communication skills. However, within busy OPCs, rushed interviews and large case volumes could diminish the effectiveness of outpatient teaching (Irby, 1995; McGee \& Irby, 1997; Stewart et al., 2005). Therefore, designating certain OPCs as teaching environments could ensure optimal patient numbers for the development of essential communication skills in trainees (Stewart et al., 2005). This would ultimately provide a setting in which instructors can efficiently observe trainee-patient interactions in order to deliver valuable feedback and promote independent learning (Almoallim et al., 2006).

In this regard, assessment tools have already been developed to evaluate the communication skills of residents within OPCs (Gigante \& Swan, 2010; Skillings et al., 2010). For example, the Set the stage, Elicit information, Give information, Understand the patient's perspective, and End the encounter (SEGUE) Framework, which is recommended by the Accreditation Council for Graduate Medical Education (ACGME), is a checklist-style rating scale that facilitates teaching and assessment of communication skills in trainees through direct observation. Notably, this framework was recently modified specifically to evaluate discrete interviewing behavior in outpatient settings (Skillings et al., 2010). Thus, the continued development of such observational tools (e.g., the mini clinical evaluation exercise [mini-CEX] for workplace-based assessment) should facilitate the ability of attending physicians to provide beneficial critiques for trainees in order to cultivate effective doctor-patient interaction skills (Hecker et al., 2012).

\subsection{Learning through Supervision}

In any clinical setting, the level and quality of trainee supervision is of great significance for learning. However, owing to the high volume of patients that pass through an OPC, training may suffer as a result of time constraints. Indeed, in a survey of junior doctors in the UK, while on-ward supervision was perceived to be acceptable, 30\% of respondents found outpatient supervision to be unsatisfactory (Panayiotou \& Fotherby, 1996). There are a number of factors that have been shown to affect the opinion of a trainee regarding training quality within an outpatient setting. Roth et al. investigated perceptions of the learning environment in ambulatory residency clinics, and identified a number of factors that contributed to the perceived quality of teaching (Roth et al., 2006), while Probst et al. assessed the significance of organizational environment (Probst et al., 1998). The authors found that the presence of structured learning opportunities contributed most to judgment of teaching quality, and suggested that regular knowledge assessment, the setting of goals, and appropriate levels of responsibility were important for improving training outcomes. The usefulness of skills assessment and feedback was also noted in a study by Wendling et al. (Wendling et al., 2004). They described the use of a resident competency evaluation strategy, and investigated its usefulness as perceived by residents in an outpatient setting. A high proportion of residents found the information provided regarding their skills to be useful, with $88 \%$ indicating that they would like the evaluation process to continue. In agreement with these findings, Dubey et al. reported that a high proportion of rheumatology trainees felt that they would benefit greatly from a 30 minute debriefing session after an OPC (Dubey et al., 2004).

There are different approaches to learner supervision, with varying levels of independence granted to the trainee (MacDougall, 2003). Azher et al. conducted a randomized controlled trial to assess the perception of surgical outpatient consultations involving medical students (Azher et al., 2013). They found that students preferred an approach by which they performed an initial interview with the patient in the absence of the doctor, which was then followed by an examination in their presence. This preference was attributed to the students' feeling more involved with the patient, and being able to communicate with them more effectively. Similarly, $92 \%$ of students who had spent time in outpatient ear, nose, and throat clinics reported that they liked to see patients alone, 
while 65\% stated that they liked to watch the doctor (Hajioff \& Birchall, 1999). Student satisfaction was higher when they saw patients alone, and was also found to correlate with appointment duration.

\section{Discussion}

Despite the lack of systematic studies regarding the advantages and disadvantages of teaching in an OPC setting, evidence from the variety of reports that we have identified in this review suggests that there are many potential benefits. With the changes to healthcare dramatically increasing outpatient numbers, the initiation of more extensive and structured OPC training programs is perhaps inescapable.

However, there are certain limitations to teaching in OPCs that may hinder the wider use of such methods. Firstly, a willingness on the part of the faculty to make changes to the traditional inpatient-based teaching approaches may not be forthcoming. The time and organizational input required to establish a new program within an already busy training schedule provides a significant barrier to its implementation. The inevitable costs of initiating OPC teaching are another drawback, although an up to date and detailed cost-benefit analysis is needed in order to clarify the current situation (Flanagan et al., 1995; Sostok et al., 1995).

The likely increase in outpatient appointment time will reduce the number of patients that can be seen during a clinic, significantly decreasing the productivity of the supervisor (Gamble \& Lee, 1991). Furthermore, attempts to minimize this burden may result in insufficient time being used for student discussion and feedback. As the evidence points to learners finding this time to be highly beneficial, insufficient input by the supervisor may have a highly negative effect on their training (Dubey, 2004). In line with this is the level of teaching skills of the supervisor. It is only recently that teacher training has become a more routine component of the professional development of physicians (Bowen \& Irby, 2002; Busari et al., 2005). If outpatient teaching was to constitute a significant proportion of a student's training, time would need to be spent on ensuring that all participating trainers displayed adequate teaching and supervision skills.

While it may be thought that a lack of willingness by patients to have a student participate in their outpatient appointment would be a problem, studies suggest that this is not a significant issue (Crawford et al., 2005; Choudhury et al., 2006; Shah-Khan et al., 2007; Al Ghamdi et al., 2014). It appears that a sufficient proportion of patients are happy to have the student present during their consultation, providing adequate cases for training purposes.

The studies that have been carried out on the topic of teaching in an OPC setting have generally been limited to a single specialty, making generalization difficult. Furthermore, it is likely that certain fields of medicine will be more suited to this approach, and future research should take this into account.

Although many questions regarding teaching in an OPC have been raised in the past, there remains inadequate evidence for the benefits to trainees (Bowen \& Irby, 2002). This may be a significant contributory factor to the slow rate at which such training is becoming part of the medical curriculum. In order to fully realize the potential benefits of teaching in an OPC setting, these questions need to be satisfactorily answered.

\section{Conclusion}

Our systematic analysis of the literature has revealed several advantages to teaching residents and students within outpatient environments, including adequate case exposure, experience with diverse clinical topics, and efficient development of doctor-patient relationships. Approaches to teaching and supervision in the outpatient setting vary greatly depending on the trainer and location of the clinic, with little consensus on the optimal strategy. Continued research within outpatient settings will be required to better understand the relationships between resident supervision, medical education, and patient outcomes in outpatient training environments.

\section{Acknowledgements}

This work was supervised and supported by the Alzaidi Chair of Research in Rheumatic Diseases at Umm Alqura University.

\section{References}

Al Ghamdi, K. M., Almohanna, H. M., Alkeraye, S. S., Alsaif, F. M., \& Alrasheed, S. K. (2014). Perceptions, Attitudes, and Satisfaction Concerning Resident Participation in Health Care among Dermatology Outpatients. Journal of Cutaneous 
Medicine and Surgery, 18, 20-27.

Albert, D. V., Brorson, J. R., Amidei, C., \& Lukas, R. V. (2014). Education Research: Case Logs in the Assessment of Medical Students in the Neurology Outpatient Clinic. Neurology, 82, e138-e141. http://dx.doi.org/10.1212/WNL.0000000000000333

Almoallim, H., Chalmers, A., \& Page, G. (2006). The High Clinic: A Pilot Project of a New Model for an Outpatient, Community-Based Teaching Clinic in Rheumatology. Medical Teacher, 28, 713-716. http://dx.doi.org/10.1080/01421590601102956

Azher, H., Lay, J., Stupart, D. A., Guest, G. D., \& Watters, D. A. (2013). Medical Student Participation in a Surgical Outpatient Clinic: A Randomized Controlled Trial. ANZ Journal of Surgery, 83, 466-471. http://dx.doi.org/10.1111/ans.12133

Behmanesh, F., Ahanchian, H., Vakili, R., Ahanchian, N., \& Bagheri, S. (2014). Teaching Final-Year Medical Students in a Paediatric Ambulatory Care Unit. The Clinical Teacher, 11, 361-364. http://dx.doi.org/10.1111/tct.12150

Bentley, J. D., Knapp, R. M., \& Petersdorf, R. G. (1989). Education in Ambulatory Care-Financing Is One Piece of the Puzzle. The New England Journal of Medicine, 320, 1531-1534. http://dx.doi.org/10.1056/NEJM198906083202306

Bowen, J. L., \& Irby, D. M. (2002). Assessing Quality and Costs of Education in the Ambulatory Setting: A Review of the Literature. Academic Medicine: Journal of the Association of American Medical Colleges, 77, 621-680. http://dx.doi.org/10.1097/00001888-200207000-00006

Busari, J. O., Weggelaar, N. M., Knottnerus, A. C., Greidanus, P. M., \& Scherpbier, A. J. (2005). How Medical Residents Perceive the Quality of Supervision Provided by Attending Doctors in the Clinical Setting. Medical Education, 39, 696703. http://dx.doi.org/10.1111/j.1365-2929.2005.02190.x

Carrese, J. A., McDonald, E. L., Moon, M., Taylor, H. A., Khaira, K., Catherine Beach, M. et al. (2011). Everyday Ethics in Internal Medicine Resident Clinic: An Opportunity to Teach. Medical Education, 45, 712-721. http://dx.doi.org/10.1111/j.1365-2923.2011.03931.x

Chatenay, M., Maguire, T., Skakun, E., Chang, G., Cook, D., \& Warnock, G. L. (1996). Does Volume of Clinical Experience Affect Performance of Clinical Clerks on Surgery Exit Examinations? American Journal of Surgery, 172, 366-372. http://dx.doi.org/10.1016/S0002-9610(96)00184-5

Choudhury, T. R., Moosa, A. A., Cushing, A., \& Bestwick, J. (2006). Patients’ Attitudes towards the Presence of Medical Students during Consultations. Medical Teacher, 28, e198-e203. http://dx.doi.org/10.1080/01421590600834336

Cook, D. A., Beckman, T. J., Thomas, K. G., \& Thompson, W. G. (2008). Introducing Resident Doctors to Complexity in Ambulatory Medicine. Medical Education, 42, 838-848. http://dx.doi.org/10.1111/j.1365-2923.2008.03108.x

Crawford, G. H., Gutman, A., Kantor, J., \& James, W. D. (2005). Patients' Attitudes toward Resident Participation in Dermatology Outpatient Clinics. Journal of the American Academy of Dermatology, 53, 710-712. http://dx.doi.org/10.1016/j.jaad.2005.05.003

Dent, J. A. (2005). Amee Guide No. 26: Clinical Teaching in Ambulatory Care Settings: Making the Most of Learning Opportunities with Outpatients. Medical Teacher, 27, 302-315. http://dx.doi.org/10.1080/01421590500150999

Dubey, S. G., Roberts, C., Adebajo, A. O., \& Snaith, M. L. (2004). Rheumatology Training in the United Kingdom: The Trainees’ Perspective. Rheumatology (Oxford), 43, 896-900. http://dx.doi.org/10.1093/rheumatology/keh192

Fincher, R. M. E., \& Albritton, T. A. (1993). The Ambulatory Experience for Junior Medical Students at the Medical College of Georgia. Teaching and Learning in Medicine, 5, 210-213. http://dx.doi.org/10.1080/10401339309539624

Flanagan, T., Mitchner, B., Weyl-Feyling, D., \& Laros Jr., R. K. (1995). The Cost of Teaching Residents Outpatient Obstetrics and Gynecology in a University Medical Center. Obstetrics and Gynecology, 86, 1014-1017. http://dx.doi.org/10.1016/0029-7844(95)00321-H

Gamble, J. G., \& Lee, R. (1991). Investigating Whether Education of Residents in a Group Practice Increases the Length of the Outpatient Visit. Academic Medicine: Journal of the Association of American Medical Colleges, 66, 492-493. http://dx.doi.org/10.1097/00001888-199108000-00019

Gigante, J., \& Swan, R. (2010). A Simplified Observation Tool for Residents in the Outpatient Clinic. Journal of Graduate Medical Education, 2, 108-110. http://dx.doi.org/10.4300/JGME-D-09-00090.1

Hajioff, D., \& Birchall, M. (1999). Medical Students in Ent Outpatient Clinics: Appointment Times, Patient Satisfaction and Student Satisfaction. Medical Education, 33, 669-673. http://dx.doi.org/10.1046/j.1365-2923.1999.00422.x

Harden, J. R., Crosby, M. H., Davis, M., \& Friedman, R. M. (1999). Amee Guide No. 14: Outcome-Based Education: Part 5-From Competency to Meta-Competency: A Model for the Specification of Learning Outcomes. Medical Teacher, 21, 546-552. http://dx.doi.org/10.1080/01421599978951

Hecker, K. G., Norris, J., \& Coe, J. B. (2012). Workplace-Based Assessment in a Primary-Care Setting. Journal of Veterinary Medical Education, 39, 229-240. http://dx.doi.org/10.3138/jvme.0612.054R

Irby, D. M. (1995). Teaching and Learning in Ambulatory Care Settings: A Thematic Review of the Literature. Academic 
Medicine: Journal of the Association of American Medical Colleges, 70, 898-931. http://dx.doi.org/10.1097/00001888-199510000-00014

Kerfoot, B. P., \& DeWolf, W. C. (2002). Does the Outpatient Setting Provide the Best Environment for Medical Student Learning of Urology? The Journal of Urology, 167, 1797-1799. http://dx.doi.org/10.1016/S0022-5347(05)65213-5

Kotur, P. F. (2012). Introduction of Evidence-Based Medicine in Undergraduate Medical Curriculum for Development of Professional Competencies in Medical Students. Current Opinion in Anaesthesiology, 25, 719-723.

http://dx.doi.org/10.1097/ACO.0b013e32835a1112

Krackov, S. K., Birskovich, L., Packman, C. H., Seward, S. J., Ragansmith, M. G., \& Baker, S. D. (1993). Perspectives on Ambulatory Programs: Barriers and Implementation Strategies. Teaching and Learning in Medicine, 5, 243-250. http://dx.doi.org/10.1080/10401339309539631

Lawson, M. M., F. (1993). Sharing Good Practice: Innovative Learning and Assessment. London: King’s Fund Centre.

MacDougall, J. (2003). On-the-Job Training: Ward and Clinic. The Obstetrician \& Gynaecologist, 5, 221-225. http://dx.doi.org/10.1576/toag.5.4.221.26936

Mariam, D. H., Sagay, A. S., Arubaku, W., Bailey, R. J., Baingana, R. K., Burani, A. et al. (2014). Community-Based Education Programs in Africa: Faculty Experience within the Medical Education Partnership Initiative (Mepi) Network. Academic Medicine: Journal of the Association of American Medical Colleges, 89, S50-S54. http://dx.doi.org/10.1097/ACM.0000000000000330

McGee, S. R., \& Irby, D. M. (1997). Teaching in the Outpatient Clinic. Practical Tips. Journal of General Internal Medicine, 12, S34-S40. http://dx.doi.org/10.1046/j.1525-1497.12.s2.5.x

Meyers, F. J., Weinberger, S. E., Fitzgibbons, J. P., Glassroth, J., Duffy, F. D., \& Clayton, C. P. (2007). Redesigning Residency Training in Internal Medicine: The Consensus Report of the Alliance for Academic Internal Medicine Education Redesign Task Force. Academic Medicine: Journal of the Association of American Medical Colleges, 82, 1211-1219. http://dx.doi.org/10.1097/ACM.0b013e318159d010

Moon, M., Taylor, H. A., McDonald, E. L., Hughes, M. T., \& Carrese, J. A. (2009). Everyday Ethics Issues in the Outpatient Clinical Practice of Pediatric Residents. Archives of Pediatrics \& Adolescent Medicine, 163, 838-843. http://dx.doi.org/10.1001/archpediatrics.2009.139

Neumayer, L., McNamara, R. M., Dayton, M., \& Kim, B. (1998). Does Volume of Patients Seen in an Outpatient Setting Impact Test Scores? American Journal of Surgery, 175, 511-514. http://dx.doi.org/10.1016/S0002-9610(98)00086-5

Panayiotou, B. N., \& Fotherby, M. D. (1996). Junior Hospital Doctors' Views on Their Training in the UK. Postgraduate Medical Journal, 72, 547-550. http://dx.doi.org/10.1136/pgmj.72.851.547

Pincavage, A. T., Razi, R. R., Arora, V. M., Oyler, J., \& Woodruff, J. N. (2013). Resident Education in Free Clinics: An Internal Medicine Continuity Clinic Experience. Journal of Graduate Medical Education, 5, 327-331. http://dx.doi.org/10.4300/JGME-D-12-00127.1

Probst, J. C., Baxley, E. G., Schell, B. J., Cleghorn, G. D., \& Bogdewic, S. P. (1998). Organizational Environment and Perceptions of Teaching Quality in Seven South Carolina Family Medicine Residency Programs. Acadameic Medicine, 73, 887-893. http://dx.doi.org/10.1097/00001888-199808000-00014

Roth, L. M., Severson, R. K., Probst, J. C., Monsur, J. C., Markova, T., Kushner, S. A. et al. (2006). Exploring Physician and Staff Perceptions of the Learning Environment in Ambulatory Residency Clinics. Family Medicine, 38, 177-184.

Seabrook, M. A., Lawson, M., \& Baskerville, P. A. (1997). Teaching and Learning in Day Surgery Units: A UK Survey. Medical Education, 31, 105-108. http://dx.doi.org/10.1111/j.1365-2923.1997.tb02467.x

Seabrook, M. A., Lawson, M., Woodfield, S., \& Baskerville, P. A. (1998). Undergraduate Teaching in a Day Surgery Unit: A 2-Year Evaluation. Medical Education, 32, 298-303. http://dx.doi.org/10.1046/j.1365-2923.1998.00208.x

Sen Gupta, T. K., Muray, R. B., McDonell, A., Murphy, B., \& Underhill, A. D. (2008). Rural Internships for Final Year Students: Clinical Experience, Education and Workforce. Rural and Remote Health, 8, 827.

Shah-Khan, M., Chowdhry, S., Brand, M. I., \& Saclarides, T. J. (2007). Patient Attitudes toward Medical Students in an Outpatient Colorectal Surgery Clinic. Diseases of the Colon and Rectum, 50, 1255-1258. http://dx.doi.org/10.1007/s10350-007-0274-x

Skillings, J. L., Porcerelli, J. H., \& Markova, T. (2010). Contextualizing Segue: Evaluating Residents’ Communication Skills within the Framework of a Structured Medical Interview. Journal of Graduate Medical Education, 2, 102-107. http://dx.doi.org/10.4300/JGME-D-09-00030.1

Sostok, M. A., Luke, R. G., \& Rouan, G. W. (1995). Confronting the Costs of Ambulatory-Care Training. Academic Medicine, 70, 949-950. http://dx.doi.org/10.1097/00001888-199511000-00003

Stahl, J. E., Balasubramanian, H. J., Gao, X., Overko, S., \& Fosburgh, B. (2014). Balancing Clinical Experience in Outpatient Residency Training. Medical Decision Making: An International Journal of the Society for Medical Decision Making, 
34, 464-472. http://dx.doi.org/10.1177/0272989X14524304

Stewart, C. I., Preece, P. E., \& Dent, J. A. (2005). Can a Dedicated Teaching and Learning Environment in Ambulatory Care Improve the Acquisition of Learning Outcomes? Medical Teacher, 27, 358-363. http://dx.doi.org/10.1080/01421590500087050

Sturm, L. A., Shultz, J., Kirby, R., \& Stelzner, S. M. (2011). Community Partners as Co-Teachers in Resident Continuity Clinics. Academic Medicine: Journal of the Association of American Medical Colleges, 86, 1532-1538. http://dx.doi.org/10.1097/ACM.0b013e3182359764

Wendling, A. L. (2004). Assessing Resident Competency in an Outpatient Setting. Family Medicine, 36, 178-184.

Wieland, M. L., Halvorsen, A. J., Chaudhry, R., Reed, D. A., McDonald, F. S., \& Thomas, K. G. (2013). An Evaluation of Internal Medicine Residency Continuity Clinic Redesign to a 50/50 Outpatient-Inpatient Model. Journal of General Internal Medicine, 28, 1014-1019. http://dx.doi.org/10.1007/s11606-012-2312-1

Yikilkan, H., Gorpelioglu, S., Aypak, C., Uysal, Z., \& Ariman, O. O. (2013). Differences between Rural and Urban Primary Care Units in Turkey: Implications on Residents’ Training. Journal of Family Medicine and Primary Care, 2, 15-19. http://dx.doi.org/10.4103/2249-4863.109935 